\title{
The liver $X$ receptor agonist T0901317 reduces the inflammation of alveolar epithelial cells induced by polyhexamethylene guanidine through inhibition of the NFKB signaling pathway
}

\author{
Lutang Wei ${ }^{1,2 \#}$, Yongzhong Guo ${ }^{3 \#}$, Xiaoqian Ding ${ }^{1}$, Caihong Guo ${ }^{1}$, Nan Ge ${ }^{4}$, Dunqiang Ren ${ }^{1,2}$, \\ Hongmei Wang ${ }^{1}$
}

${ }^{1}$ Department of Respiratory and Critical Care Medicine, The Affiliated Hospital of Qingdao University, Qingdao, China; ${ }^{2}$ Department of Environmental and Occupational Health, School of Public Health, Qingdao University, Qingdao, China; ${ }^{3}$ Department of Respiratory and Critical Care Medicine, Xuzhou Central Hospital, The Xuzhou School of Clinical Medicine of Nanjing Medical University, Xuzhou Clinical School of Xuzhou Medical University, Xuzhou, China; ${ }^{4}$ Department of Thoracic Surgery, The Affiliated Hospital of Qingdao University, Qingdao, China.

Contributions: (I) Conception and design: D Ren; (II) Administrative support: D Ren, H Wang; (III) Provision of study materials or patients: D Ren; (IV) Collection and assembly of data: L Wei, Y Guo; (V) Data analysis and interpretation: X Ding, C Guo, N Ge, D Ren; (VI) Manuscript writing: All authors; (VII) Final approval of manuscript: All authors.

\#These authors contributed equally to this work.

Correspondence to: Dunqiang Ren. Department of Respiratory and Critical Care Medicine, The Affiliated Hospital of Qingdao University, Qingdao, China. Email:rdq1982@163.com.

Background: As a kind of disinfectant, polyhexamethylene guanidine (PHMG) can cause pulmonary inflammation. In addition to liver X receptors (LXRs) playing an important role in cholesterol and lipid metabolism, it has also been found to be involved in inflammation in recent years. This article explores the role of LXRs agonist T0901317 in the inflammation of alveolar epithelial cells induced by PHMG.

Methods: The A549 human alveolar basal epithelial cell line was exposed to PHMG, T0901317, or the nuclear factor (NF)кB inhibitor BAY11-7082. The cell survival rate was used to determine the cytotoxicity of PHMG and T0901317 to A549 cells. Western blot analysis was used to determine the expression of proteins related to the LXRs and the NFאB signaling pathway. Enzyme-linked immunosorbent assay (ELISA) was conducted to examine the expression of inflammatory cytokines such as interleukin (IL)-8 and interleukin (IL)-6. Results: Incubation of A549 cells with PHMG decreased the expression of LXRs-related proteins, reduced

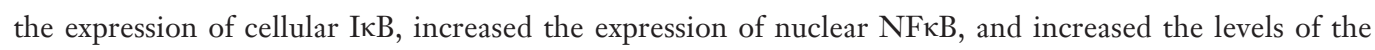
inflammatory cytokineIL-8 and IL-6. However, pretreatment with the LXR agonist T0901317 partially reversed the effects of PHMG. The effects of T0901317 on NFאB signaling pathway was similar to that observed with the NFкB inhibitor BAY11-7082.

Conclusions: The LXRs agonist T0901317 may reduce the inflammation of alveolar epithelial cells induced by PHMG by inhibiting the NFKB signaling pathway.

Keywords: Liver X receptors (LXRs); polyhexamethylene guanidine (PHMG); NFкB; IL-8; A549

Submitted Nov 05, 2021. Accepted for publication Dec 22, 2021.

doi: 10.21037/atm-21-6501

View this article at: https://dx.doi.org/10.21037/atm-21-6501

\footnotetext{
^ ORCID: 0000-0002-9601-7899.
} 


\section{Introduction}

Polyhexamethylene guanidine (PHMG), which belongs to the guanidine family of antiseptics, is widely used in aquaculture, shampoo, wet wipes, disinfectants, and other household products because it is colorless, odorless, soluble in water, has a wide range of disinfectant activity, and other desirable properties (1-4). Prior to 2010, most toxicity studies on PHMG focused on oral and percutaneous toxicity. The median lethal dose $\left(\mathrm{LD}_{50}\right)$ of oral exposure to PHMG in Sprague Dawley (SD) rats is $500-600 \mathrm{mg} / \mathrm{kg}$, suggesting that PHMG is an acute low-toxicity substance. Therefore, the health risks and hidden dangers of guanidine cationic disinfectants, especially respiratory toxicity, has failed to attract much attention. As an excellent disinfectant, PHMG is widely used in daily life. However, in 2011, there was an incident of lung injury caused by guanidine cationic disinfectants in humidifiers in South Korea. Respiratory exposure to PHMG not only caused acute lung injury (ALI), which resulted in the death of pregnant women and children, but also caused pulmonary fibrosis in thousands of patients, affecting their quality of life and life expectancy. This incident provided a warning regarding the health risks and hazards caused by inhalation exposure of guanidine cationic disinfectants (5-7).

Since then, many scientists have performed in vivo and in vitro studies examining the mechanisms of lung injury caused by PHMG $(8,9)$. Many studies have shown that PHMG can induce nuclear factor $(\mathrm{NF}) \mathrm{\kappa B}$-mediated inflammation, such as the release of cytokines and chemokines in the lungs (10-12). NFkB is a key factor in the inflammatory response. When unstimulated, NFкB binds to I $\mathrm{B}$ as a dimer of P50 and P65 to form a stable complex with no transcriptional activity. Under stimulation from inflammatory factors, I $\mathrm{B}$ dissociates from the complex and $\mathrm{NF \kappa B}$ is activated and translocates into the nucleus. It then binds to the promoter regions of inflammatory cytokines such as tumor necrosis factor- $\alpha$ (TNF- $\alpha)$, interleukin- 6 (IL-6), and interleukin-8 (IL-8), in the nucleus to induce transcription and translation of related genes (13).

The liver $X$ receptor (LXR $\alpha$ and LXR $\beta$ ), which belongs to the superfamily of nuclear receptors, is a ligand-dependent receptor that controls diverse pathways involved in development, reproduction, metabolism, and inflammation. LXR $\alpha$ is mainly distributed in the liver, intestine, kidney, spleen, lungs, adipose tissue, mononuclear macrophages, and airway smooth muscle cells, while LXR $\beta$ is expressed in almost all tissues (14). Studies have shown that the expression of LXRs is down-regulated during lung inflammation and injury caused by lipopolysaccharides (LPSs) and other stimuli. LXR activation can inhibit NFkB activity and reduce lung inflammation and lung injury induced by LPSs and other stimuli (15-17). To date, there is a paucity of research examining the role of LXRs in pulmonary inflammation and fibrosis caused by PHMG. We speculate that the expression of LXRs is down-regulated in PHMG-induced alveolar epithelial cell inflammation and the LXR agonist T0901317 may reduce PHMG-induced alveolar epithelial inflammation by restoring the expression of LXRs and inhibiting the activation of the NFкB signaling pathway. This study examined the cytotoxicity of alveolar epithelial cells after treatment with PHMG and T0901317. The expression of LXRs-related proteins, NFкB-related proteins, and the inflammatory cytokine IL-8 and IL-6 was detected by Western blot analysis and enzyme-linked immunosorbent assay (ELISA). The results demonstrated that the LXR agonist T0901317 may reduce the inflammation of alveolar epithelial cells induced by PHMG by inhibiting the NFkB signaling pathway.

We present the following article in accordance with the MDAR reporting checklist (available at https://dx.doi. org/10.21037/atm-21-6501).

\section{Methods}

\section{Cell culture}

The human A549 alveolar epithelial cell line was obtained from Peking University Medical Laboratory (Beijing, China) and cultured in RPMI-1640 medium supplemented with $10 \%$ fetal bovine serum, 100 units $/ \mathrm{mL}$ penicillin, and $100 \mu \mathrm{g} / \mathrm{mL}$ streptomycin. The cells were cultured at $37^{\circ} \mathrm{C}$ and $5 \% \mathrm{CO}_{2}$ according to the American Type Culture Collection (ATCC) recommendations.

\section{Cell viability assays}

The survival rate of A549 cells was assessed using the Cell Counting Kit 8 (Meilun Biotech, Dalian, China). The A549 cells were plated in 96-well plates at a density of $10 \times 10^{3}$ cells/well and cultured for 24 hours. PHMG 0-32 $\mu \mathrm{g} / \mathrm{mL}$ (High Polymer Bio, Shanghai, China) and

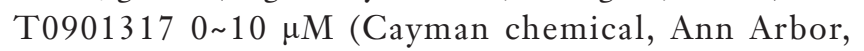
Michigan, USA) were added to each well at different concentrations. After 6, 24 and 48 hours, the Cell Counting Kit 8 (CCK-8) solution $(10 \mu \mathrm{L})$ was added to each well and 

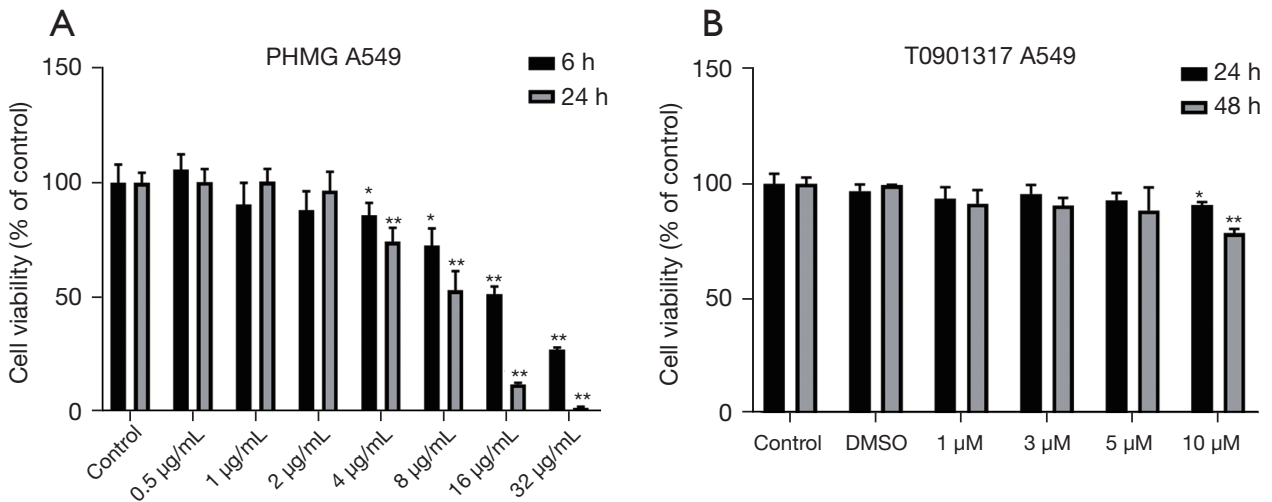

Figure 1 The cytotoxicity of PHMG and T0901317 to A549 cells. (A) A549 cells were exposed to PHMG (0-32 $\mu \mathrm{g} / \mathrm{mL})$ for 6 hours and 24 hours. (B) A549 cells were exposed to T0901317 (0-10 $\mu \mathrm{M})$ for 24 and 48 hours. Cell viability was assessed using the CCK-8 assay and expressed as a percentage of the control cells (mean $\pm \mathrm{SD}$ ). * $\mathrm{P}<0.05$ compared to control; ** $\mathrm{P}<0.01$ compared to control. PHMG, polyhexamethylene guanidine; DMSO, dimethyl sulfoxide; CCK-8, Cell Counting Kit 8; SD, standard deviation.

cells were incubated at $37^{\circ} \mathrm{C}$ for 1 hour. The absorbance at $450 \mathrm{~nm}$ was detected with a microplate reader (Tecan company, Austria).

\section{Western blot analysis}

The A549 cells were cultured in $6 \mathrm{~cm}$ dishes until $70 \%$ confluency. Cells were then stimulated with the corresponding reagents for 24 hours, followed by 3 washes with phosphate buffered saline (PBS). The total protein, cytoplasmic protein, and nuclear protein were extracted from the cells using the Nuclear protein Extraction Kit (Solarbio, Beijing, China). Protein concentration was measured using the BCA protein concentration determination kit (Solarbio, Beijing, China). Protein samples $(30 \mu \mathrm{g})$ were separated by electrophoresis on a $10 \%$ gel, transferred onto polyvinylidene fluoride (PVDF) membranes, and blocked with $5 \%$ skimmed milk powder for 1 hour at room temperature. Membranes were then incubated with the primary antibodies against SREBP (sc13551, Santa Cruz Biotechnology), LXR $\alpha / \beta$ (sc-377260, Santa Cruz Biotechnology), IкB (ab32518, Abcam), or NFкB (ab32536, Abcam) overnight, followed by incubation with the secondary antibody 1 hour. The PVDF membrane was developed under a chemical imaging analyzer (Fusion FX7 Vilber Lourmat, Paris, France). The ImageJ software was used for quantification and the density of each band was normalized to that of glyceraldehyde 3-phosphate dehydrogenase (GAPDH; \#2118, Cell Signaling Technology) or lamin B (abs131244, Absin Bioscience).

\section{Cytokine measurement by ELISA}

A549 cells were exposed to PHMG (at a final concentration $4 \mu \mathrm{g} / \mathrm{mL}$ ), T0901317 [at a final concentration of $1 \mu \mathrm{M}$, diluted with $1 \%$ o dimethyl sulfoxide (DMSO)], or the NFkB inhibitorBAY11-7082 (at a final concentration of $20 \mu \mathrm{M}$; MCE, Shanghai, China) for 24 hours. The supernatant was collected and the levels of IL-8 and IL-6 were quantified using ELISA (Elabscience, Wuhan, China) according to the manufacturer's protocols.

\section{Statistical analysis}

The data were expressed by mean \pm standard deviation (SD). Statistical analyses were conducted using Prism 8.0.1 software (GraphPad Software, Inc., USA). Differences between multiple groups were assessed by one-way analysis of variance (ANOVA). Differences between two groups were assessed using the student's $t$-test. A P value $<0.05$ or $<0.01$ was considered statistically significant.

\section{Results}

\section{The cytotoxicity of PHMG and T0901317 to A549 cells}

Exposure of A549 cells to PHMG showed a dose-dependent cytotoxic effect. Significant cytotoxicity was observed in A549 cells at PHMG concentrations greater than $4 \mu \mathrm{g} / \mathrm{mL}$ after both 6 and 24 hours. PHMG had little effect on the proliferation of A549 cells at concentrations lower than $2 \mu \mathrm{g} / \mathrm{mL}$ (Figure $1 A$ ). 
When A549 cells were exposed to the LXR agonist for 24 and 48 hours, cytotoxic was only observed at a concentration of $10 \mu \mathrm{M}$. At $5 \mu \mathrm{M}$ or lower, T0901317 had no cytotoxic effect on A549 cells. Furthermore, DMSO had no significant cytotoxic effect on A549 cells (Figure 1B).

\section{T0901317 reverses the down-regulation of LXR-related proteins in A549 cells induced by PHMG exposure}

The expression of LXR $\alpha$ and LXR $\beta$ decreased when A549 cells were exposed to PHMG ( $4 \mu \mathrm{g} / \mathrm{mL})$. In addition, the expression of sterol regulatory element binding protein (SREBP), a LXR downstream specific target protein, was also decreased. In cells treated with PHMG and T0901317 (the PHMG + T09 group), the expression of LXRs and SREBP was increased compared to cells treated with PHMG alone. DMSO had little effect on the expression of LXRs-related proteins (Figure 2A,2B).

\section{T0901317 inbibits the activation of the NFrB signaling pathway caused by PHMG exposure}

When A549 cells were exposed to PHMG ( $4 \mu \mathrm{g} / \mathrm{mL})$, the expression of IкB decreased compared with control cells, while the expression of nuclear NFкB increased. Conversely, cells in the PHMG + T09 group showed increased expression of I $\kappa$ B compared to cells treated with PHMG alone, while the expression of nuclear NFkB decreased. Similarly, incubation with PHMG and the NFkB inhibitor BAY11-7082 (PHMG $+\mathrm{BAY}$ ) reduced the expression of nuclear NFкB protein. There was little change in the expression of NFкB-related proteins in the DMSO group and the T0901317 group compared to the control group (Figure $2 C-2 G$ ).

\section{T0901317 inbibits the expression of inflammatory cytokine IL-8 and IL-6 caused by PHMG exposure in A549 cell}

The expression of IL-8 and IL-6 was significantly increased in A549 cells treated for 24 hours with PHMG $(4 \mu \mathrm{g} / \mathrm{mL})$ compared to control cells. Addition of the LXRs agonist T0901317 to cells treated with PHMG (the PHMG + T09 group) significantly reduced the expression of IL-8 and IL-6 compared to that observed in cells treated with PHMG alone. Furthermore, addition of BAY11-7082 to cells treated with PHMG significantly decreased the expression of IL-8 and IL-6 compared to cells treated with PHMG alone. DMSO and T0901317 had no effect significant effect on the expression of IL-8 and IL-6 in A549 cells (Figure 3A,3B).

\section{Discussion}

Since the Korean humidifier lung injury incident, many studies have been performed to understand the mechanisms by which PHMG and its related guanidine disinfectants cause lung inflammation $(10,18-22)$ and pulmonary fibrosis (12,22-26). One study showed that exposure of mouse macrophage RAW264.7 cells to PHMG decreased ІкB protein expression, increased $\mathrm{NF \kappa B}$ luciferase activity, and elevated the expression of inflammatory cytokines IL-1 $\beta$, IL-6, and IL-8. However, addition of the NFкB inhibitor BAY11-7082 completely abolished the increase of IL-8 caused by PHMG, suggesting that PHMG induces inflammation through the NFkB signaling pathway (10). Kim et al. demonstrated that exposure of A549 cells to polyhexamethylene biguanide (PHMB) decreased IкB expression, increased nuclear $\mathrm{NF \kappa B}$ expression, and elevated the levels of IL-8, IL-6, and TNF- $\alpha$. Adding WP9QY (TNF- $\alpha$ inhibitor) and N-acetylcysteine (ROS antioxidant) partially inhibited the expression of IL-8 caused by PHMB. By the way, the JNK inhibitor SP600125 could also partially inhibit the PHMG-induced expression of IL-6 and TNF- $\alpha$ in A549 cells (21). However, addition of the NFкB inhibitor completely inhibited the expression of IL-8, suggesting that PHMB induces inflammation through the NFкB signaling pathway (18). Our in vitro experiments suggested that PHMG can cause the degradation of the I $\kappa$ B protein in A549 cells, thereby releasing $\mathrm{NF \kappa B}$. Activated NFKB enters the nucleus from the cytoplasm and promoted the transcription and translation of downstream inflammatory genes. This investigation also demonstrated that the expression of the inflammatory cytokine IL-8 and IL-6 was increased after PHMG exposure. However, the NFkB inhibitor BAY11-7082 decreased the expression of nuclear $\mathrm{NF \kappa B}$ and its downstream inflammatory cytokine IL-8 and IL-6, suggesting that PHMG can induce inflammation through the NFkB signaling pathway. Previous in vivo studies have shown that PHMG can cause lung inflammation and fibrosis in mice $(12,23,25)$ and this is consistent with our preliminary animal investigations (27).

The LXRs were originally thought to be nuclear receptors that play a key role in lipid homeostasis. Studies have now shown that LXRs also have anti-inflammatory and anti-fibrotic effects in vitro and in vivo (15,16,28-31). Therefore, we speculated that LXRs might be involved in the pathogenesis of lung inflammation, and activation of the LXR signaling pathway might protect the alveolar epithelial cell inflammation caused by PHMG. Indeed, the results 
A
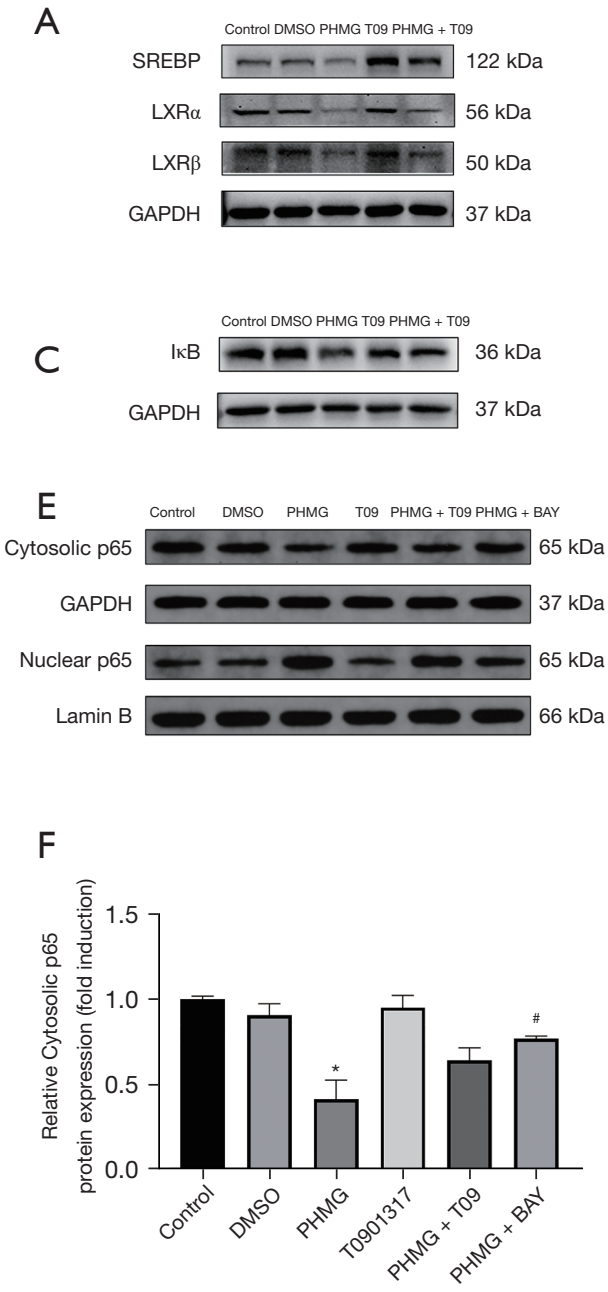

B
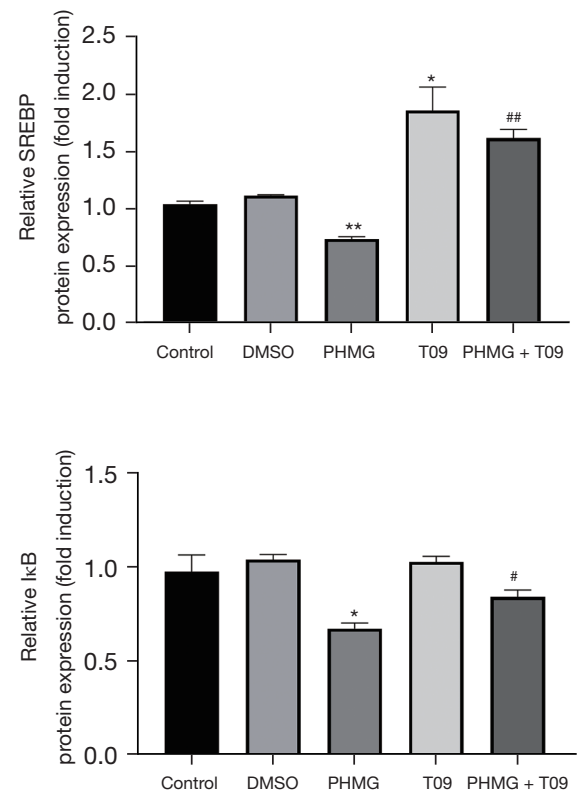

G

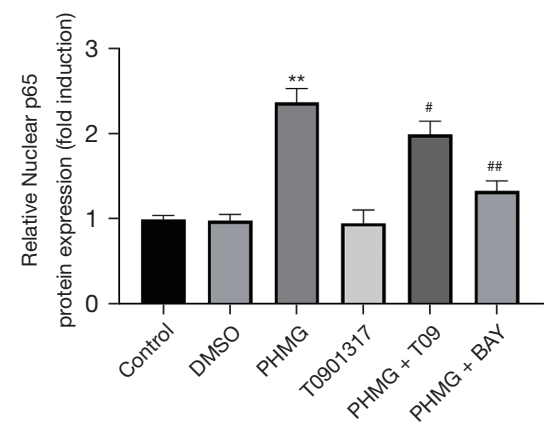

Figure 2 The effects of PHMG and T0901317 on LXRs and NFkB related proteins. A549 cells were exposed to PHMG (4 $\mu \mathrm{g} / \mathrm{mL})$,

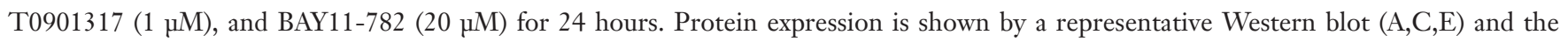
corresponding bar graph (B,D,F,G). The relative abundance of each protein was normalized to that of GAPDH or lamin B. ${ }^{*}, \mathrm{P}<0.05$ and **, $\mathrm{P}<0.01$ compared to control cells; ${ }^{\#}, \mathrm{P}<0.05$ and ${ }^{\# \#}, \mathrm{P}<0.01$ compared to PHMG-treated cells. DMSO, dimethyl sulfoxide; PHMG, polyhexamethylene guanidine; LXR, liver X receptor; NF, nuclear factor; GAPDH, glyceraldehyde 3-phosphate dehydrogenase; T09, T0901317; BAY, BAY11-7082.

of this study showed that PHMG exposure decreased the expression of LXR $\alpha$ and LXR $\beta$ in A549 alveolar epithelial cells. Interestingly, pretreatment with the LXRs agonist T0901317 restored the expression of LXR $\alpha$ and LXR $\beta$ in PHMG-exposed alveolar epithelial cells. These results demonstrated that in the alveolar epithelial cells treated with PHMG, the NFкB signaling pathway is activated, and the expression of the downstream inflammatory cytokine IL-8 and IL-6 are increased. Pretreatment with T0901317 inhibited the $\mathrm{NF} \kappa \mathrm{B}$ signaling pathway and reduced the expression of downstream IL-8 and IL-6 expression. Indeed, the effects of T0901317 on inflammatory factors were similar to that observed with NFкB inhibitors, suggesting that T0901317 may reduce PHMG-induced inflammation of alveolar epithelial cells by inhibiting the NFאB signaling pathway. A previous study showed that LXR agonists in human umbilical vein endothelial cells (HUVECs) not only dose-dependently inhibited the lysophosphatidylcholine (LPC)-induced increase in IL-8, but also reversed the induction of LPC-mediated NFKB activation. Moreover, LXR agonists also inhibited the binding of $\mathrm{NF \kappa B}$ to the IL-8 promoter induced by LPC in HUVECs, suggesting 
A

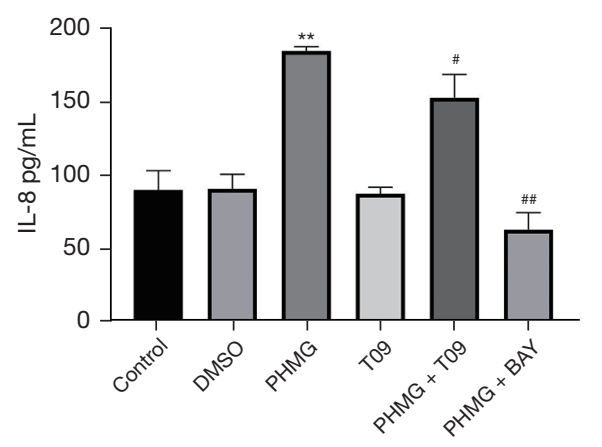

B

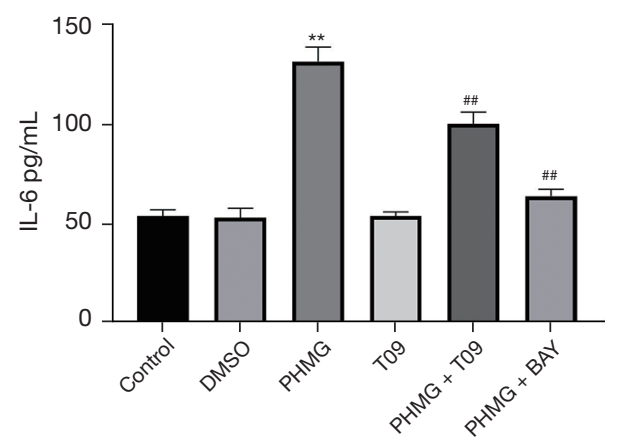

Figure 3 The expression of inflammatory cytokine IL-8 (A) and IL-6 (B) in A549 cells treated with PHMG (4 $\mu$ g/mL), T0901317 (1 $\mu$ M), and BAY11-782 (20 $\mu \mathrm{M})$. The data are expressed as mean $\pm \mathrm{SD}$. ${ }^{* *}, \mathrm{P}<0.01$ compared to control cells; ${ }^{\#}, \mathrm{P}<0.05$ and ${ }^{\# \#}, \mathrm{P}<0.01$ compared to cells treated with PHMG. IL-8, interleukin-8; IL-6, interleukin-6; PHMG, polyhexamethylene guanidine; DMSO, dimethyl sulfoxide; T09, T0901317; BAY, BAY11-7082; SD, standard deviation.

that the inhibitory effect of LXR-mediated inflammation was partly related to the $\mathrm{NF \kappa B}$ pathway (28). Other investigations using rat models have also reported that ALI induced by LPSs decreased the expression of LXR $\alpha$ / $\beta$, increased the expression of inflammatory cytokines IL- $1 \beta$, IL-6, and TNF- $\alpha$, and elevated the expression of NFкB. The LXRs were activated after treatment with T0901317 and the expression of NFkB decreased, as did the expression of inflammatory cytokines, such as IL-1 $\beta$. This suggested that the mechanism by which T0901317 reduces the inflammatory response in ALI rats may be related to the inhibition of $\mathrm{NF \kappa B}$ activation (15). Another report showed that intraperitoneal injection of high-dose paraquat resulted in decreased expression of LXR-related proteins, lung inflammation, and ALI in mice. IкB expression was decreased, expression of TNF- $\alpha$ and IL- $1 \beta$ was increased, as was the expression of nuclear NFкB. Furthermore, antioxidant enzyme activity was reduced. The pro-apoptotic gene Bax was up-regulated and the apoptotic gene Bcl-2 was down-regulated. After intraperitoneal injection of the LXRs agonist T0901317, the expression of LXR-related proteins was restored, and all the above changes were reversed by inhibiting the NFKB and JNK/p38 MAPK signaling pathways, and exerting an anti-inflammatory, antioxidant, and anti-apoptotic effect (16).

To the best of our knowledge, this current investigation is the first to report the effects of PHMG on the expression of LXR-related proteins in A549 cells, and the effects of the LXR agonist T0901317 on the inflammation of alveolar epithelial cells induced by PHMG. There were some limitations to this study. First, the experiments were performed in vitro, and no in vivo studies were performed. Then, the role of oxidative stress in this process has not been discussed. In addition, no experiments related to cell morphology detection were conducted. Finally, although the results suggested that the activation of the LXRs might reduce PHMG-induced inflammation of A549 cells by inhibiting the NFKB signaling pathway, the role of $L X R \alpha$ or $\mathrm{LXR} \beta$ in this process remains to be elucidated and further researches warranted.

\section{Acknowledgments}

Funding: This work was supported by the National Science Foundation of China (No. 81300046). The funding agencies had no further roles in the design of the study, the collection, analysis, and interpretation of data, nor the writing of the manuscript.

\section{Footnote}

Reporting Checklist: The authors have completed the MDAR reporting checklist. Available at https://dx.doi. org/10.21037/atm-21-6501

Data Sharing Statement: Available at https://dx.doi. org/10.21037/atm-21-6501

Conflicts of Interest: All authors have completed the ICMJE uniform disclosure form (available at https://dx.doi. 
org/10.21037/atm-21-6501). The authors have no conflicts of interest to declare.

Ethical Statement: The authors are accountable for all aspects of the work in ensuring that questions related to the accuracy or integrity of any part of the work are appropriately investigated and resolved.

Open Access Statement: This is an Open Access article distributed in accordance with the Creative Commons Attribution-NonCommercial-NoDerivs 4.0 International License (CC BY-NC-ND 4.0), which permits the noncommercial replication and distribution of the article with the strict proviso that no changes or edits are made and the original work is properly cited (including links to both the formal publication through the relevant DOI and the license). See: https://creativecommons.org/licenses/by-nc-nd/4.0/.

\section{References}

1. Li NN, Yu W. Research progress in the performance and application of polyhexamethyleneguanidine disinfectants. Daily Chemical Science 2015;38:36-39.

2. Tang JL, Zhu XX, Zheng YX. Progress in respiratory toxicity of polyhexamethyleneguaidine disinfectant and mechanism exploration. Zhonghua Yu Fang Yi Xue Za Zhi 2020;54:209-12.

3. Qu WD. Concern about lung damage caused by guanidine cationic disinfectants. Zhonghua Yu Fang Yi Xue Za Zhi 2020;54:121-3.

4. Jeong MH, Kim HR, Park YJ, et al. Akt and Notch pathways mediate polyhexamethylene guanidine phosphate-induced epithelial-mesenchymal transition via ZEB2. Toxicol Appl Pharmacol 2019;380:114691.

5. Park DU, Ryu SH, Lim HK, et al. Types of household humidifier disinfectant and associated risk of lung injury (HDLI) in South Korea. Sci Total Environ 2017;596597:53-60.

6. Shin DY, Jeong MH, Bang IJ, et al. MicroRNA regulatory networks reflective of polyhexamethylene guanidine phosphate-induced fibrosis in A549 human alveolar adenocarcinoma cells. Toxicol Lett 2018;287:49-58.

7. Kim MS, Han JY, Kim SH, et al. Oleanolic acid acetate attenuates polyhexamethylene guanidine phosphateinduced pulmonary inflammation and fibrosis in mice. Respir Physiol Neurobiol 2018;252-253:1-9.

8. Li X, Zhang J, Du C, et al. Polyhexamethylene guanidine aerosol triggers pulmonary fibrosis concomitant with elevated surface tension via inhibiting pulmonary surfactant. J Hazard Mater 2021;420:126642.

9. Zhu X, Kong X, Ma S, et al. TGF $\beta /$ Smad mediated the polyhexamethyleneguanide areosol-induced irreversible pulmonary fibrosis in subchronic inhalation exposure. Inhal Toxicol 2020;32:419-30.

10. Kim HR, Shin DY, Chung KH. The role of NF-кB signaling pathway in polyhexamethylene guanidine phosphate induced inflammatory response in mouse macrophage RAW264.7 cells. Toxicol Lett 2015;233:148-55.

11. Kim JY, Kim HH, Cho KH. Acute cardiovascular toxicity of sterilizers, PHMG, and PGH: severe inflammation in human cells and heart failure in zebrafish. Cardiovasc Toxicol 2013;13:148-60.

12. Song JA, Park HJ, Yang MJ, et al. Polyhexamethyleneguanidine phosphate induces severe lung inflammation, fibrosis, and thymic atrophy. Food Chem Toxicol 2014;69:267-75.

13. Peng C, Ouyang Y, Lu N, et al. The NF-кB Signaling Pathway, the Microbiota, and Gastrointestinal Tumorigenesis: Recent Advances. Front Immunol 2020;11:1387.

14. Cannon MV, van Gilst WH, de Boer RA. Emerging role of liver $\mathrm{X}$ receptors in cardiac pathophysiology and heart failure. Basic Res Cardiol 2016;111:3.

15. Wang D, Liu M, Wang Y, et al. Synthetic LXR agonist T0901317 attenuates lipopolysaccharide-induced acute lung injury in rats. Int Immunopharmacol 2011;11:2098-103.

16. Hu X, Shen H, Wang Y, et al. Liver X Receptor Agonist TO901317 Attenuates Paraquat-Induced Acute Lung Injury through Inhibition of NF- $\kappa \mathrm{B}$ and JNK/p38 MAPK Signal Pathways. Biomed Res Int 2017;2017:4652695.

17. Smoak K, Madenspacher J, Jeyaseelan S, et al. Effects of liver $\mathrm{X}$ receptor agonist treatment on pulmonary inflammation and host defense.J Immunol 2008;180:3305-12.

18. Kim HR, Shin DY, Chung KH. In vitro inflammatory

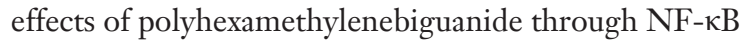
activation in A549 cells. Toxicol In Vitro 2017;38:1-7.

19. Vitt A, Slizen V, Boström EA, et al. Effects of polyhexamethylene guanidine phosphate on human gingival fibroblasts. Acta Odontol Scand 2017;75:524-9.

20. Oh H, Kim CY, Ryu B, et al. Respiratory Toxicity of Polyhexamethylene Guanidine Phosphate Exposure in Zebrafish. Zebrafish 2018;15:460-72.

21. Kim MS, Han JY, Kim SH, et al. Polyhexamethylene guanidine phosphate induces IL- 6 and TNF- $\alpha$ expression 
through JNK-dependent pathway in human lung epithelial cells. J Toxicol Sci 2018;43:485-92.

22. Kim HR, Lee K, Park CW, et al. Polyhexamethylene guanidine phosphate aerosol particles induce pulmonary inflammatory and fibrotic responses. Arch Toxicol 2016;90:617-32.

23. Kim MS, Kim SH, Jeon D, et al. Changes in expression of cytokines in polyhexamethylene guanidine-induced lung fibrosis in mice: Comparison of bleomycin-induced lung fibrosis. Toxicology 2018;393:185-92.

24. Kim MS, Kim SH, Jeon D, et al. Low-dose cadmium exposure exacerbates polyhexamethylene guanidineinduced lung fibrosis in mice. J Toxicol Environ Health A 2018;81:384-96.

25. Song J, Kim W, Kim YB, et al. Time course of polyhexamethyleneguanidine phosphate-induced lung inflammation and fibrosis in mice. Toxicol Appl Pharmacol 2018;345:94-102.

26. Song MK, Kim DI, Lee K. Time-course transcriptomic alterations reflect the pathophysiology of polyhexamethylene guanidine phosphate-induced lung injury in rats. Inhal Toxicol 2019;31:457-67.

Cite this article as: Wei L, Guo Y, Ding X, Guo C, Ge N, Ren D, Wang H. The liver X receptor agonist T0901317 reduces the inflammation of alveolar epithelial cells induced by polyhexamethylene guanidine through inhibition of the $\mathrm{NF \kappa B}$ signaling pathway. Ann Transl Med 2021;9(24):1795. doi: 10.21037/atm-21-6501
27. Zhu XX, Meng T, Leng SG, et al. Study on fibrosis changes in the lungs of mice caused by repeated inhalation of polyhexamethyleneguaidine disinfectant. Zhonghua Yu Fang Yi Xue Za Zhi 2020;54:198-202.

28. Bi X, Song J, Gao J, et al. Activation of liver X receptor attenuates lysophosphatidylcholine-induced IL-8 expression in endothelial cells via the NF- $\mathrm{NB}$ pathway and SUMOylation. J Cell Mol Med 2016;20:2249-58.

29. Solan PD, Piraino G, Hake PW, et al. Liver X receptor $\alpha$ activation with the synthetic ligand T0901317 reduces lung injury and inflammation after hemorrhage and resuscitation via inhibition of the nuclear factor $\kappa \mathrm{B}$ pathway. Shock 2011;35:367-74.

30. Wang X, Yan J, Xu X, et al. Puerarin prevents LPSinduced acute lung injury via inhibiting inflammatory response. Microb Pathog 2018;118:170-6.

31. Wang Y, Li C, Cheng K, et al. Activation of liver $\mathrm{X}$ receptor improves viability of adipose-derived mesenchymal stem cells to attenuate myocardial ischemia injury through TLR4/NF-кB and Keap-1/Nrf-2 signaling pathways. Antioxid Redox Signal 2014;21:2543-57. 